\title{
Erratum to: Patient-centered imaging
}

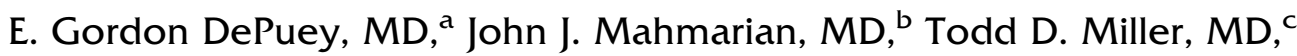 \\ Andrew J. Einstein, $\mathrm{MD}, \mathrm{PhD},{ }^{\mathrm{d}}$ Christopher L. Hansen, $\mathrm{MD},{ }^{\mathrm{e}}$ \\ Thomas A. Holly, MD, ${ }^{\mathrm{f}}$ Edward J. Miller, MD, PhD, ${ }^{\mathrm{g}}$ Donna M. Polk, MD, MPH, ${ }^{\mathrm{h}}$ \\ and L. Samuel Wann, MD, PhD ${ }^{\mathrm{i}}$
}

\section{ERRATUM TO: J NUCL CARDIOL DOI 10.1007/S1 2350-012-9523-Z}

Unfortunately, the following corrections were not incorporated into the original article.

- On page 14 under Pharmacologic Agents in the 3rd paragraph, reference \#72 should be removed after "asthma"

- On page 14 under Pharmacologic Agents in the 3rd paragraph, reference \#74 should be added after "COPD"

- On page 14 under Pharmacologic Agents in the 4th paragraph, reference \#74 is incorrect after "results" and should be reference \#75

- On page 17 under The Patient with Acute Chest Pain in the ED in the 4th paragraph, reference \#93 after "infarction" should be removed
- On page 22 under The "Caffeinated" Patient Unable to Exercise in the 2nd paragraph, reference \#134 is incorrect after "Zoghbi et al" and should be reference \#75

- On page 22 under The "Caffeinated" Patient Unable to Exercise in the 2nd paragraph, reference \#134 should be added after "hyperemia" at the end of the last sentence

- On page 31 under the References, the order of references \#159 and 160 should be switched

- On page 23 under The Patient Pre-/Post-Transplant in the 3rd paragraph, reference \#160 should be added after "respectively)."

- On page 23 under The Patient Pre-/Post-Transplant in the 3rd paragraph, reference \#160 should be removed after "CAD." The correct references listed after "CAD." Should be \#161-162.
The online version of the original article can be found under doi:10.1007/s12350-012-9523-z.

From the St. Luke's-Roosevelt Hospital, ${ }^{a}$ New York, NY; Methodist DeBakey Heart and Vascular Center, ${ }^{\text {b }}$ Houston, TX; Mayo Clinic, ${ }^{c}$ Rochester, MN; Columbia University Medical Center, ${ }^{\mathrm{d}}$ New York, NY; Jefferson Heart Institute, ${ }^{\mathrm{e}}$ Philadelphia, PA; Northwestern University, ${ }^{\mathrm{f}}$ Chicago, IL; Boston University School of Medicine, ${ }^{\mathrm{g}}$ Boston, MA; Hartford Hospital, ${ }^{\text {h }}$ Hartford, CT; and Wheaton Franciscan Medical Group, ${ }^{\text {i }}$ Milwaukee, WI.

Reprint requests: E. Gordon DePuey, MD, St. Luke's-Roosevelt Hospital, New York, NY.

J Nucl Cardiol 2012;19:633.

$1071-3581 / \$ 34.00$

Copyright (c) 2012 American Society of Nuclear Cardiology.

doi:10.1007/s12350-012-9540-y 